\title{
Machine Vision is an Image Based Technique Used in Inspection
}

\author{
Chandra Mohan M, Dhanasekar.J, V.Priya
}

\begin{abstract}
In this Project, rigging and screw string parameters are estimated with the machine vision innovation. It gives a minimal effort answer for modern robotization. Right off the bat, picture edge is separated from the apparatus/screw utilizing picture preparing technique. Also, utilizing fundamental geometry parameters from the plan information book, different parameters can be distinguished utilizing non-contact machine vision systems. In light of machine vision, this venture utilizes the picture handling innovation for screw and apparatus parameters identification through non-contact techniques. This work presents a few strategies for picture preparing, for example, pre-handling, morphological activity, and other related technology. Edge location strategy can be utilized to compute the apparatus projection successful distance across. The discovery techniques will be progressively right and compelling. What's more, it is absolutely founded on picture preparing to improve the estimation speed and precision. It has better functional incentive in the real. The outcomes will be contrasted and the deliberate qualities by the conventional estimation strategy.
\end{abstract}

Keywords : Robotization, Precision,Machine Vision

\section{INTRODUCTION}

This undertaking depends on picture handling innovation. Picture preparing is handling of pictures utilizing scientific activities by utilizing any type of sign handling for which the information is a picture, a progression of pictures, or a video, for example, a photo or video outline; the yield of picture preparing might be either a picture or a lot of attributes or parameter identified with the image. This work presents a few strategies for picture handling, for example, picture securing, pre-handling, morphological activity, edge upgrade, and other related innovation. What's more, it is simply founded on picture handling to improve the estimation speed and precision. It gives a minimal effort answer for mechanical computerization. The outcomes will be contrasted and the deliberate qualities by the conventional estimation technique.

\section{EXISTING SYSTEM}

\section{A. Contact Measurement System}

An arrange estimating machine with inflexible opposite arms. Contact 3D scanners test the subject through physical touch, while the article is in contact with or laying on an accuracy level surface plate, ground and cleaned to a particular limit of surface harshness[10]. Where the article to be examined isn't level or can't lay steadily on a level surface, it is upheld and held immovably set up by an installation.

\section{B. Vernier Caliper}

A caliper is a gadget used to gauge the separation between two rival sides of an item. It tends to be as straightforward as a compass with internal or outward-confronting focuses. First the tips of the caliper are changed in accordance with fit over the focuses to be estimated and the caliper is then evacuated and the separation between the tips is estimated utilizing a ruler.

\section{Screw Gauge}

The screw check is an instrument utilized for estimating precisely the breadth of a slender wire or the thickness of a sheet of metal. It comprises of a U-formed casing fitted with a screwed axle which is joined to a thimble Parallel to the pivot of the thimble, a scale graduated in $\mathrm{mm}$ is engraved. This is called pitch scale[8]. A sleeve is connected to the leader of the screw.

\section{Limitations In Existing System}

The real disservice is that we use contact standard which may harm fragile item and the calculation time is moderate[9]. It is in the scope of $100 \mathrm{~Hz}$. Single sweep won't create a total model of the article. Subsequently numerous output from various heading are generally required to get data pretty much all sides of item. Additionally it requires regular reference framework

Rigging and screw are the mechanical parts which has prime need in everyday life[7].

The Quality control of rigging and screw fabricating industry has a lot of strategies for avoidance of "false endorsement" and "genuine dismissal" in quality check.

The vast majority of the geometric parameters of riggings and screws are tried physically by standard scales and checks which experiences numerous confinements

\section{E. Limitations \\ - $\quad$ Prone to error \\ Damage to parts \\ Time consuming}

Revised Manuscript Received on August 22, 2019.

Chandra Mohan M, Department of Mechatronics, Bharath Institute of Higher Education and Research, Chennai, Tamilnadu, India. Email: indiranimohan1993@gmail.com

Dhanasekar. J, Department of Mechatronics, Bharath Institute of Higher Education and Research, Chennai, Tamilnadu, India. Email: Jdhanasekar81@gmail.com

V.Priya, Department of Mechatronics, Bharath Institute of Higher Education and Research, Chennai, Tamilnadu, India. Email: priyaygna14@gmail.com 


\section{PROPOSED SYSTEM}

Machine vision is a picture based procedure utilized in investigation. The picture is gotten from the camera and is stacked to the PC which at that point experiences a few pictures handling calculation and gives the outcome in screen. This procedure is a computerized procedure and henceforth profoundly exact and exact estimations can be gotten.

\section{Advantages}

- Multiple parameters can be acquired in single run. For e.g. In a Spur Gear, diameter, Base circle radius, No. of teeth can be found in single run of the machine

- The time taken by the process is very low compared to manual process.

- As the parts were not tested by conventional contact system i.e. testing using gauges ad scales, this system is more reliable in terms of finish quality

- The scope of this system is very much[10].

\section{BLOCK DIAGRAM}

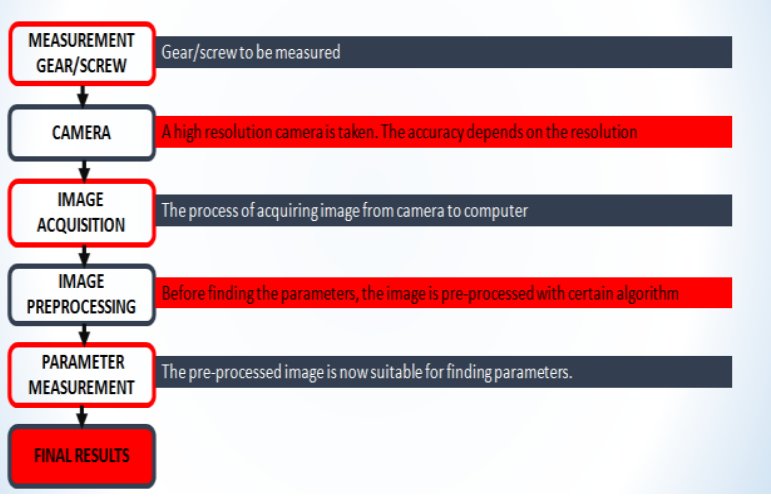

\section{METHODOLOGY}

Focal point emanates the light onto the item set on the acrylic sheet. Acrylic sheet expands the radiance and consequently utilized in transmission of light. Item is enlightened by the focal point and subsequently it is caught as a picture by a camera. The camera is put over the article by methods for tripod[8].The camera is put over the item by methods for tripod. Picture acquired is $2 \mathrm{D}$ and its further handled to get the subtleties of a picture. When the parameters of the article are acquired, it is contrasted and standard worth. The outcomes acquired will demonstrate the deviation of the article's parameter. This data of the picture is nourished to the PC and further handling is finished. We get the picture from the camera and read the rgb picture. The picture is changed over from rgb to dark scale picture. The dim picture is then changed over into double picture with limit esteem. The paired picture is changed over to supplement of the picture.

The picture is expanded by utilizing morphological activity with a basic component. The supplement of the picture is then filled to take out the key entire from the picture. Utilizing the proper guidance the centroid of the picture is found. The edge of the picture is identified with a reasonable edge administrator[9]. After identification of edge the directions of the each edge is found.

The good ways from the centroid to each edge pixel is discovered utilizing circling activity which is the external distance across of the item. The widening activity is done on the picture. Further the picture is handled by the accessible information. The aftereffect of the item is shown on the screen.
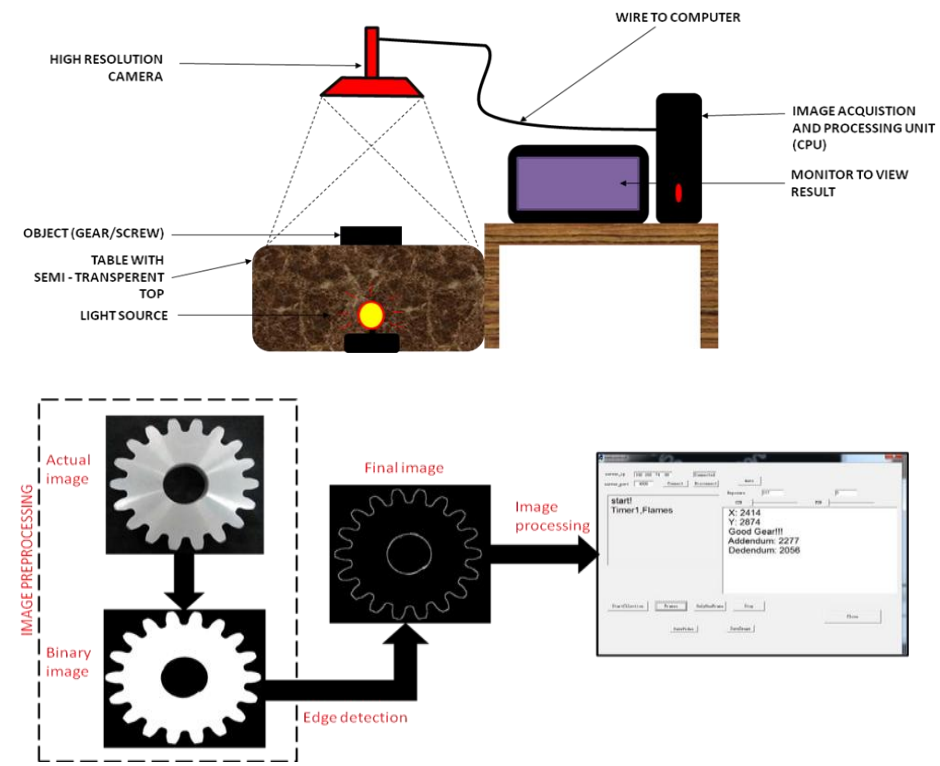

Figure - 1 Sample Process
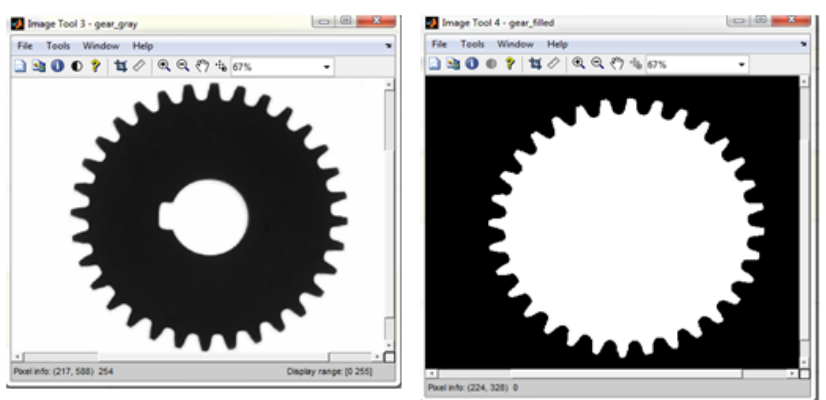

Figure 2 - Gear gray scale image, Gear Filled Image
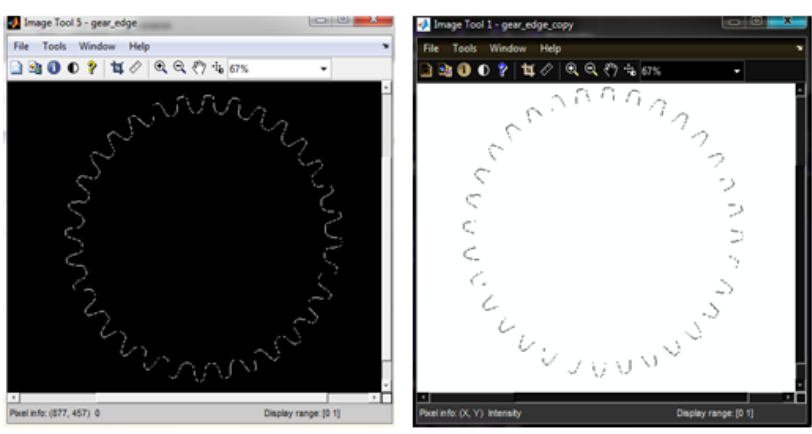

Figure 3 - Gear edge image, Gear teeth edge Image

Published By: Blue Eyes Intelligence Engineering \& Sciences Publication 


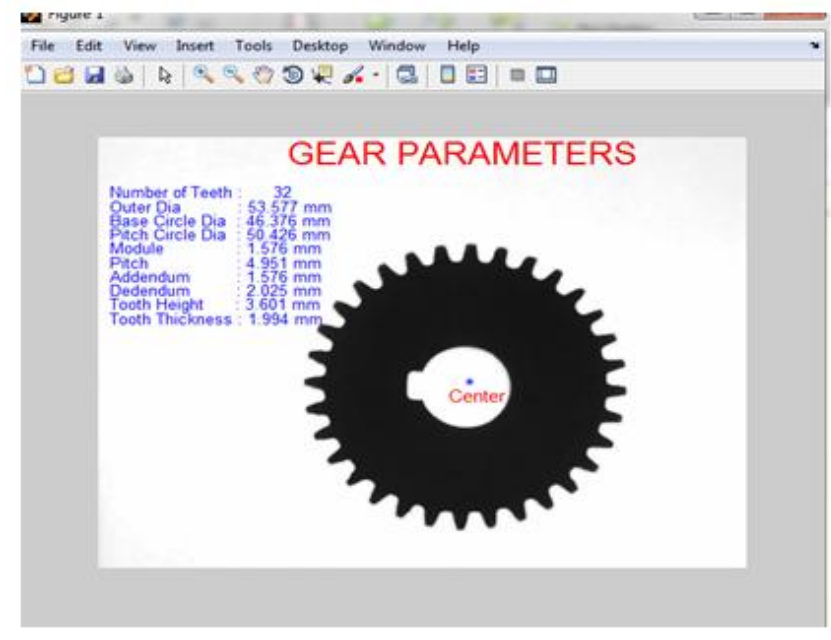

Figure 4 - Gear Parameters output

\section{CONCLUSION}

Thus the process to automate the measuring and analysing of gear and cable parameter has been done. This reduces human labour and the time invested in measuring as in conventional processes. Moreover the entire results were said to be accurate and helps in better computation. This can be extended in near future to analyse another set of objects using the same image processing technology.

\section{REFERENCES}

1. Dhanasekar, J., Sengottuvel, P. \& Palanikumar, K. 2019, "Implementation of effective fuel saving methodology for turbines using air drag in vehicles", Materials Today: Proceedings, pp. 421

2. Kumar, S.S., Kumar, K.S.R. \& Kumar, N. 2018, "Experimental evaluation of magnetorheological damper characteristics for vibration analysis", International Journal of Vehicle Structures and Systems, vol. 10, no. 1, pp. 30-34.

3. Dhamodaran, K., Adikesavana, P., Shankar, P.P. \& Gowtham, S. 2018, "Conceptual development of flapping wing for unmanned aerial vehicles: Technical note", International Journal of Vehicle Structures and Systems, vol. 10, no. 1, pp. 43-45.

4. Karthikeyan, S., Raman Balasubramanian, S.R., Ramesh, B., Raghul, S. \& Sathish Kumar, S. 2019, "The automatic solar tracker chronicles", International Journal of Recent Technology and Engineering, vol. 8, no. 1, pp. 312-315.

5. Hema, R., Sundararajan, M. \& Balaji, S. 2019, "Smartphone control robot with automatic firing gun", International Journal of Innovative Technology and Exploring Engineering, vol. 8, no. 9 Special Issue 3, pp. 625-627.

6. Balambica, V., Deepak, V. \& Kumar, S. 2019, "Design and efficiency of an asymmetric gear", International Journal of Mechanical and Production Engineering Research and Development, vol. 9, no. 3, pp. 223-230.

7. Saravana, S., Balaji, S., Arulselvi, S. \& John Paul Praveen, A. 2019, "Reliable power quality monitoring and protection system", International Journal of Innovative Technology and Exploring Engineering, vol. 8, no. 9 Special Issue 3, pp. 644-645.

8. Bycil, V.J. \& Wiselin, M.C.J. 2019, "Modeling and analysis of vibration energy harvesting system using piezo stack", International Journal of Mechanical and Production Engineering Research and Development, vol. 9, no. Special Issue 1, pp. 523-533.

9. Sripada, A., Warrier, A., Kapoor, A., Gaur, H. \& Hemalatha, B. 2018, "Dynamic lateral balance of humanoid robots on unstable surfaces", International Conference on Electrical,
Electronics, Communication Computer Technologies and Optimization Techniques, ICEECCOT 2017, pp. 539.

10. Mahalakshmi, V. \& Vijayaragavan, S.P. 2019, "PV based power electronic converters for high voltage DC applications", International Journal of Recent Technology and Engineering, vol. 7, no. 6, pp. 670-674.

\section{AUTHORS PROFILE}

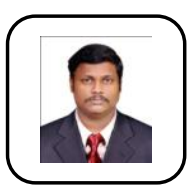

Chandra Mohan M Assistant Professor, Departmen of Mechatronics, Bharath Institute of Higher Education and Research, Chennai, India.

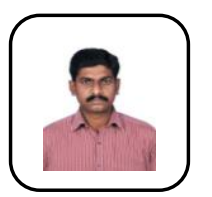

Dhanasekar. J Assistant Professor, Department of Mechatronics, Bharath Institute of Higher Education and Research, Chennai, India.

V.Priya Assistant Professor, Department of Mechatronics, Bharath Institute of Higher Education and Research, Chennai, India. 